\title{
Activity of Classical and Alternative Pathways of Complement in Preterm and Small for Gestational Age Infants
}

\begin{abstract}
LUIGI D. NOTARANGELO, ${ }^{(19)}$ GAETANO CHIRICO, ALBERTO CHIARA, ANGELO COLOMBO, GIORGIO RONDINI, ALESSANDRO PLEBANI, ALBERTO MARTINI, AND ALBERTO G. UGAZIO
\end{abstract}

Department of Pediatrics and Division of Neonatal Pathology, University of Pavia and Ospedale San Matteo, Pavia, Italy

\begin{abstract}
Summary
Complement activity was compared in $\mathbf{5 0}$ low birth weight infants divided into appropriate and small for gestational age groups; the influence of birth weight and gestational age on complement development was also investigated. $\mathrm{CH}_{50}$ and kinetics $\left(\mathrm{tH}_{50}\right)$ of both classical and alternative pathway activity of complement, C3, and Factor B levels were significantly higher in small for gestational age infants (classical pathway $\mathrm{CH}_{50}, 630$ $\mathrm{HU} / \mathrm{ml} \pm 184 \mathrm{SD} ; \mathrm{CP} \mathrm{tH}_{50}, 77 \mathrm{~min} \pm 47$; aternative pathway $\mathrm{CH}_{50}, 44.8 \mathrm{HU} / \mathrm{ml} \pm 11.3 ; \mathrm{AP} \mathrm{tH}_{50}, 56 \mathrm{~min} \pm 43 ; \mathrm{C} 3,73.98$ $\mathrm{mg} / \mathrm{dl} \pm 12.68$; and Factor $B, 13.17 \mathrm{mg} / \mathrm{dl} \pm 3.67)$ than in weight-matched appropriate for gestational age infants (CP $\mathrm{CH}_{50}, 523 \mathrm{HU} / \mathrm{ml} \pm 152 ; \mathrm{CP}$ tH $_{50}, 105 \mathrm{~min} \pm 49 ; \mathrm{AP} \mathrm{CH}_{50}$, $38.8 \mathrm{HU} / \mathrm{ml} \pm 13 ; \mathrm{AP}_{\mathrm{tH}}, 90 \mathrm{~min} \pm 53 ; \mathrm{C} 3,58.14 \mathrm{mg} / \mathrm{dl} \pm$ 9.43; and Factor $B, 9.32 \mathrm{mg} / \mathrm{dl} \pm 1.73$ ). Complement values were lower in low birth weight infants than in adult controls $(P<$ 0.001 in all cases). All complement parameters were mainly correlated with gestational age; $\mathrm{CH}_{50}$ values of the classical and alternative pathways were also highly correlated with each other ( $r=0.64 ; P<0.001)$.

Low birth weight infants, especially preterm infants, have an important defect of complement activity. Complement factors increase gradually during gestation and intrauterine growth retardation does not affect complement development. Classical and alternative complement pathway activities have a similar development pattern.
\end{abstract}

\section{Abbreviations}

AGA, appropriate for gestational age

AP, alternative pathway

CP, classical pathway

EA, antibody-sensitized sheep erythrocytes

$\mathrm{HU} / \mathrm{ml}$, hemolitic unit/ml

RaRBC, rabbit red blood cells

SGA, small for gestational age

Several studies have reported reduced activity of both $\mathrm{CP}$ and AP of complement in term newborn infants as compared with their mothers or adult controls (9). Given the importance of the serum complement system in the host's defense mechanism against infection (10), this reduction may partially explain the increased susceptibility of newborn infants to infection.

Complement activity is lower in low birth weight infants than in term infants; however, the relationship of gestational age and/ or birth weight to the level of complement activity is still controversial $(1,6,8,14,16)$. The purpose of the present study was to investigate the effects of birth weight and gestational age on complement development $\left(\mathrm{CH}_{50}\right.$ and kinetics of both $\mathrm{CP}$ and AP, C3, and Factor B levels) in low birth weight infants divided into appropriate and small for gestational age groups.

\section{PATIENTS AND METHODS}

We studied 50 healthy low birth weight babies, 25 AGA and 25 SGA, according to standard growth charts (4). AGA included 13 males and 12 females and SGA eight males and 17 females. Twelve normal term newborns (seven males and five females) were also included in the study. Gestational age was estimated by the method of Dubowitz et al. (7) and by maternal menstrual dates. Apgar at 5 min was $\geqslant 8$ in all infants. Infection, hemolytic disease of the newborn, respiratory distress, congenital malformation, or other serious disease precluded entry into the study. Neither infection nor prolonged rupture of the membranes were present in mothers.

Venous blood $(0.5 \mathrm{ml})$, obtained within $48 \mathrm{~h}$ after birth (mean, $13 \mathrm{~h}$ ), was allowed to clot and the sera were stored in liquid nitrogen until analysis. Serum samples from 35 healthy adult volunteers were stored in the same fashion. Informed consent was obtained from babies' parents.

$C P$ activity. A modified Mayer's technique adapted for microtiter plates was used (11). Briefly, $60 \mu \mathrm{l}$ of a $1 \%$ suspension of EA in veronal buffered saline pH 7.5 were added to each well containing $180 \mu \mathrm{l}$ of serum diluted in veronal buffered saline in order to have a final EA concentration of $0.25 \%$ and a final serum dilution ranging from $1 / 160$ to $1 / 320$. Four different serum concentrations were used in each assay. In order to satisfy von Krogh's equation (11), lower serum dilutions were employed whenever defective results were obtained with the above dilutions. After $30 \mathrm{~min}$ incubation at $37^{\circ} \mathrm{C}$, the optical density was measured at $492 \mathrm{~nm}$ using a microELISA photometer (Titertek Multiskan Flow Laboratory) and compared with the optical density of a standard hemolysis curve obtained by mixing suitable amounts of unlysed $0.25 \% \mathrm{EA}$ in veronal buffered saline and $0.25 \%$ EA lysed by freezing for $10 \mathrm{~min}$ in liquid nitrogen. The $\mathrm{CH}_{50}(\mathrm{HU} / \mathrm{ml})$ was calculated according to Mayer (11). The percentage of hemolysis was also measured after $0,10,20,30$, $45,60,90,120$, and $150 \mathrm{~min}$ of incubation and the time necessary to reach $50 \%$ hemolysis with the $1 / 240$ serum dilution, $\mathrm{tH}_{50}$, was calculated by plotting time $(\mathrm{x})$ versus percentage of hemolysis (y).

AP activity. A modified Ishizaka and Platts-Mill's technique adapted for microtiter plates was used (13). Briefly, $60 \mu \mathrm{l}$ of a $2 \%$ suspension of RaRBC in veronal buffered saline containing $2 \mathrm{mM} \mathrm{MgSO}_{4}$ and $0.01 \mathrm{M}$ EGTA ( $\mathrm{pH} \mathrm{7.5)} \mathrm{were} \mathrm{added} \mathrm{to} \mathrm{each}$ 
well containing $180 \mu \mathrm{l}$ of serum diluted in the same buffer to a final concentration of $\mathrm{RaRBC}$ of $0.5 \%$ and to final serum concentrations ranging from $1: 8$ to $1: 16$. Four different dilutions were used for each serum. $\mathrm{CH}_{50}(\mathrm{HU} / \mathrm{ml})$ was calculated as described above for the CP. The standard hemolysis curve was prepared by mixing suitable quantities of unlysed and lysed $0.5 \%$ $\mathrm{RaRBC}$. The time necessary to reach $50 \%$ hemolysis using the 1:12 serum dilution, $\mathrm{tH}_{50}$, was calculated by plotting time (x) versus percentage of hemolysis (y). As reported elsewhere (12), this microtechnique assures highly accurate and reproducible results for both complement pathways.

Effect of $\operatorname{Ig} G$ on the AP activity. The AP activity was assessed in the serum of a preterm infant (IgG levels $=860 \mathrm{mg} / \mathrm{dl}$ ) before and after addition of various concentrations $(100-1600 \mathrm{mg} / \mathrm{dl})$ of human standard globulins. The serum of a term newborn (IgG levels, $1300 \mathrm{mg} / \mathrm{dl}$ ) served as control.

C3 and Factor B levels determination. C3 and Factor B levels in the 50 low birth weight were determined by single radial immunodiffusion, $\mathrm{C} 3$ levels were assessed by employing Behring LC Partigen C3c plates (Lot. 055825). Factor B levels were assessed by employing Kallestad Endoplate Factor B test kit (Lot. P0589).

Statistical analysis. Statistical analysis was performed by calculating the mean, the standard deviation, the correlation coefficient (by the least square method) and Student's $t$ test.

\section{RESULTS}

The data are summarized in Table 1 and 2. As for the 35 healthy adults, mean values $\pm \mathrm{SD}$ were as follows: $\mathrm{CP}, \mathrm{CH}_{50}=$ $1167 \pm 113$ and $\mathrm{tH}_{50}, 30 \pm 1 ; \mathrm{AP}, \mathrm{CH}_{50}=96 \pm 16$ and $\mathrm{tH}_{50}=$ $10 \pm 2 ; \mathrm{C} 3,130 \pm 47$; and Factor B, $18.7 \pm 3.2$. AGA and SGA infants had comparable mean birth weights whereas mean gestational age was significantly higher in the SG.A infants.

$C P$ activity. In normal term newborns, activity $\left(\mathrm{CH}_{50}\right.$ and $\mathrm{tH}_{50}$ ) was significantly lower than in adults, but significantly higher than in AGA whereas normal term newborn and SGA activity were not significantly different (Table 2). CP activity, as estimated by both $\mathrm{CH}_{50}$ and $\mathrm{tH}_{50}$, was significantly higher in SGA than in AGA infants (Table 1). All but two low birth weight infants had CP activity below the $95 \%$ confidence interval for adult controls. No sex differences were found. In the overall population of low birth weight infants no significant correlation was found between birth weight and $\mathrm{CH}_{50}$ but the correlation between gestational age and both $\mathrm{CH}_{50}$ and $\mathrm{tH}_{50}$ were highly significant (Fig. $1 \mathrm{~A}$ and B). The $\mathrm{tH}_{50}$ was also significantly correlated with birth weight $(r=0.29, P<0.05)$.

AP activity. In the normal term newborns $\mathrm{CH}_{50}$ and $\mathrm{tH}_{50}$ activity was significantly lower than in adults but significantly higher than in AGA whereas activity of term newborn and SGA were not significantly different (Table 2). Only two low birth weight infants had $\mathrm{CH}_{50}$ values within the $95 \%$ confidence interval for adult controls. Mean values of $\mathrm{CH}_{50}$ and $\mathrm{tH}_{50}$ were significantly higher in SGA than in AGA infants (Table 1). No sex differences in $\mathrm{AP} \mathrm{CH}_{50}$ or $\mathrm{tH}_{50}$ were found. In the overall population of low birth weight infants correlations between gestational age and both $\mathrm{CH}_{50}$ and $\mathrm{tH}_{50}$ were highly significant (Fig. 2A and B).

Birth weight and $\mathrm{CH}_{50}$ were also statistically correlated ( $r=$ $0.278, P<0.05)$ but the correlation coefficient was rather low. Birth weight and $\mathrm{tH}_{50}$ were not significantly correlated. $\mathrm{CH}_{50}$

Table 2. Statistical significance of the differences ( $P$ values) in classical and alternative pathway complement activity between the study groups using Student's t test (comparison of SGA with AGA infants is reported in Table 1$)^{*}$

\begin{tabular}{|c|c|c|c|c|c|}
\hline & \multicolumn{2}{|c|}{$\begin{array}{c}\text { Normal term } \\
\text { newborns }\end{array}$} & \multicolumn{3}{|c|}{ Adult controls } \\
\hline & $\begin{array}{c}v s \\
\text { SGA }\end{array}$ & $\begin{array}{c}v s \\
\mathrm{AGA} \\
\end{array}$ & $\begin{array}{c}v s \\
\text { Normal } \\
\text { term } \\
\text { newborns }\end{array}$ & $\begin{array}{c}v s \\
\text { SGA }\end{array}$ & $\begin{array}{c}v s \\
\mathrm{AGA}\end{array}$ \\
\hline \multicolumn{6}{|l|}{$\begin{array}{l}\text { Classical } \\
\text { pathway }\end{array}$} \\
\hline $\mathrm{CH}_{50}$ & NS & $<0.05$ & $<0.001$ & $<0.001$ & $<0.001$ \\
\hline $\mathrm{tH}_{50}$ & NS & $<0.05$ & $<0.001$ & $<0.001$ & $<0.001$ \\
\hline \multicolumn{6}{|l|}{$\begin{array}{l}\text { Alternative } \\
\text { pathway }\end{array}$} \\
\hline $\mathrm{CH}_{50}$ & NS & $<0.05$ & $<0.001$ & $<0.001$ & $<0.001$ \\
\hline $\mathrm{tH}_{50}$ & NS & $<0.01$ & $<0.001$ & $<0.001$ & $<0.001$ \\
\hline $\mathrm{C} 3$ & not done & not done & not done & $<0.001$ & $<0.001$ \\
\hline Factor B & not done & not done & not done & $<0.001$ & $<0.001$ \\
\hline
\end{tabular}

* Abbreviations: SGA, small for gestational age; AGA, appropriate for gestational age; NS, not significant.

Table 1. Comparison of classical and alternative pathway complement activity in normal term newborns and in appropriate for gestational age $(A G A)$ and small for gestational age (SGA) low birth weight infants*

\begin{tabular}{|c|c|c|c|c|}
\hline & \multirow{2}{*}{$\begin{array}{c}\text { Normal term } \\
\text { newborns }\end{array}$} & \multicolumn{3}{|c|}{ Low birth weight infants } \\
\hline & & SGA & AGA & $P$ valuet \\
\hline No of patients & 12 & 25 & 25 & \\
\hline Birth weight (g) & $\begin{array}{l}3350 \pm 232 \\
(2960-3800)\end{array}$ & $\begin{array}{c}2085 \pm 869 \\
(1100-2500)\end{array}$ & $\begin{array}{c}2151 \pm 692 \\
(1400-2500)\end{array}$ & NS $\ddagger$ \\
\hline Gestational age (wk) & $\begin{array}{c}39.5 \pm 1.3 \\
(38-42)\end{array}$ & $\begin{array}{r}38.4 \pm 2.1 \\
\quad(34-42)\end{array}$ & $\begin{array}{c}34.9 \pm 1.7 \\
(31-37)\end{array}$ & $<0.01$ \\
\hline Classical pathway & $650 \pm 121$ & $630 \pm 184$ & $523 \pm 152$ & $<0.05$ \\
\hline $\mathrm{CH}_{50}(\mathrm{HU} / \mathrm{ml})$ & $(476-800)$ & $(\mathrm{nd}+-893)$ & (nd-809) & \\
\hline $\mathrm{tH}_{50}(\min )$ & $\begin{array}{c}75 \pm 43 \\
(150-30)\end{array}$ & $\begin{array}{c}77 \pm 47 \\
(>150-29)\end{array}$ & $\begin{array}{l}105 \pm 49 \\
(>150-30)\end{array}$ & $<0.05$ \\
\hline $\begin{array}{l}\text { Alternative pathway } \mathrm{CH}_{50}(\mathrm{HU} / \\
\mathrm{ml})\end{array}$ & $\begin{array}{l}46.7 \pm 8.2 \\
(31.2-55.5)\end{array}$ & $\begin{array}{c}44.8 \pm 11.3 \\
(\text { nd-70) }\end{array}$ & $\begin{array}{c}38.8 \pm 13 \\
(26-65)\end{array}$ & $<0.05$ \\
\hline $\mathrm{tH}_{50}(\min )$ & $\begin{array}{c}50 \pm 38 \\
(150-20)\end{array}$ & $\begin{array}{c}56 \pm 43 \\
(>150-14)\end{array}$ & $\begin{array}{c}90 \pm 53 \\
(>150-14)\end{array}$ & $<0.01$ \\
\hline $\mathrm{C} 3(\mathrm{mg} / \mathrm{dl})$ & not done & $\begin{array}{c}73.98 \pm 12.68 \\
(46-99)\end{array}$ & $\begin{array}{c}58.14 \pm 9.43 \\
(42-77)\end{array}$ & $<0.001$ \\
\hline Factor B (mg/dl) & not done & $\begin{array}{c}13.17 \pm 3.67 \\
(8.75-23) \\
\end{array}$ & $\begin{array}{c}9.32 \pm 1.73 \\
(5.25-13) \\
\end{array}$ & $<0.001$ \\
\hline
\end{tabular}

* Results are expressed as mean $\pm \mathrm{SD}$; range in parentheses.

$\dagger$ Statistical differences between AGA and SGA infants using Student's $t$ test.

$\ddagger$ nd, not detectable and NS, not significant. 

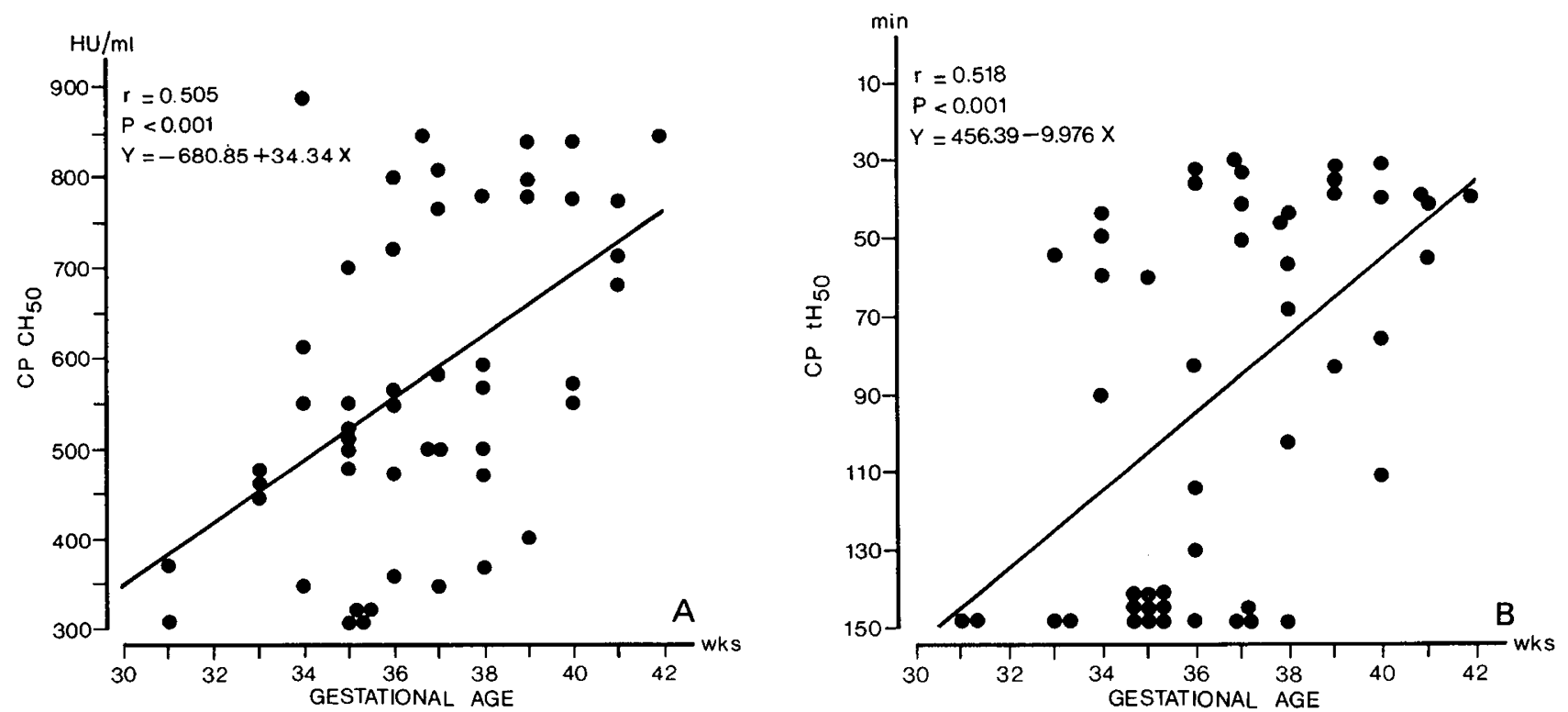

Fig. 1. Relationship of classical pathway $\mathrm{CH}_{50}\left(\mathrm{CP} \mathrm{CH}_{50}\right)$ to gestational age (left hand panel) and classical pathway th $\mathrm{H}_{50}\left(\mathrm{CP}_{\mathrm{t}} \mathrm{H}_{50}\right)$ to gestational age (right hand panel) in low birth weight newborn infants.
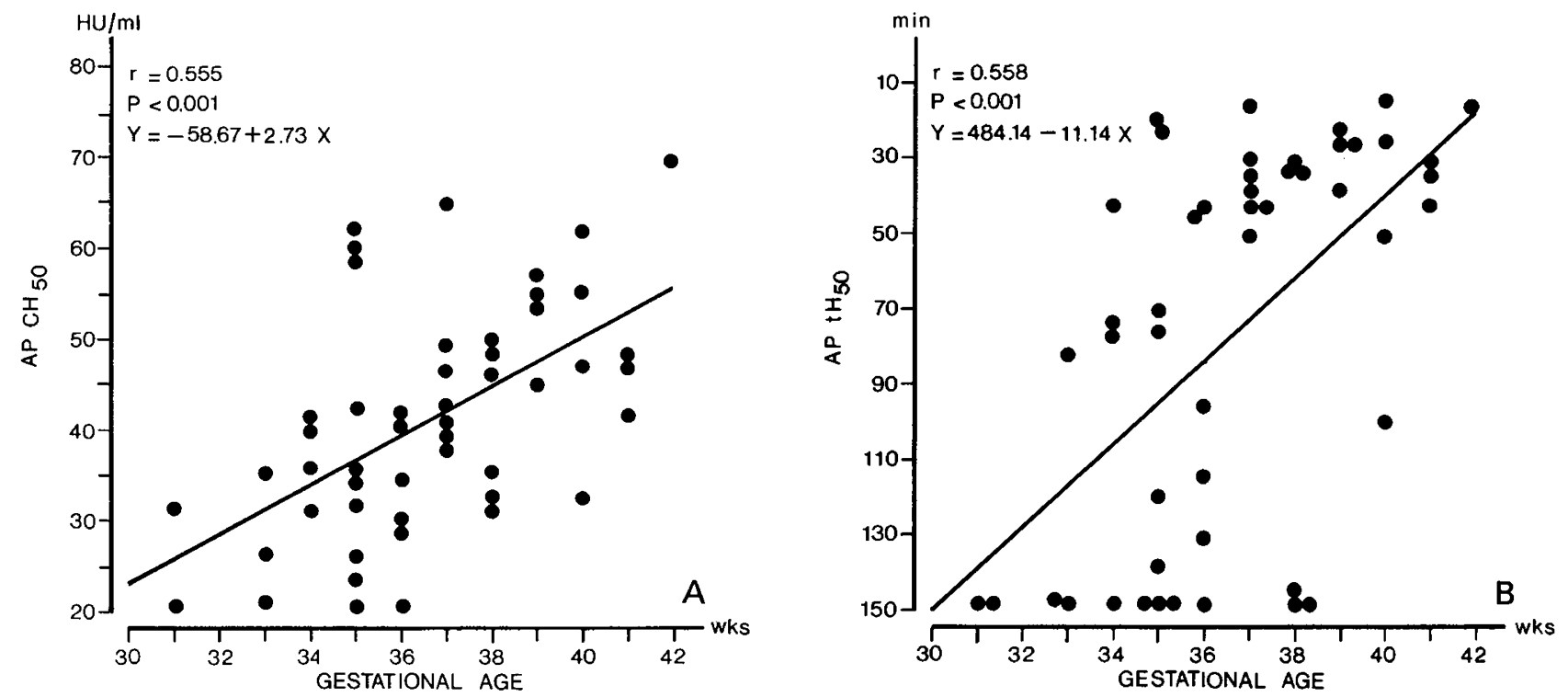

Fig. 2. Relationship of alternative pathway $\mathrm{CH}_{50}\left(\mathrm{AP} \mathrm{CH}_{50}\right)$ to gestational age (left hand panel) and alternative pathway th $\mathrm{H}_{50}\left(\mathrm{AP}\right.$ tH $\left.\mathrm{H}_{50}\right)$ to gestational age (right hand panel) in low birth weight newborn infants.

values of $C P$ and AP were highly correlated (Fig. 3). In Figure 4 examples of the kinetic pattern of AP activation in a preterm infant (gestational age, $31 \mathrm{wk}$ ), a term infant and an adult control are presented for comparison. In vitro addition of IgG (up to $1600 \mathrm{mg} / \mathrm{dl}$ ) to the serum of the preterm infant did not appreciably affect AP activity (data not shown).

$C 3$ and Factor $B$ levels. $\mathrm{C} 3$ and Factor B levels in low birth weight infants were significantly lower than in normal adult population (Table 2). A highly significant correlation was found between gestational age and $\mathrm{C} 3$ (Fig. 5) and between gestational age and Factor B (Fig. 6). A lower but significant correlation was found between $\mathrm{C} 3$ and birth weight $(r=0.289, P<0.05)$ and between Factor B and birth weight $(r=0.275, P<0.05)$.

\section{DISCUSSION}

Despite antibiotic therapy, infections remain a challenging problem in newborn infants. The complement system, via both the $\mathrm{CP}$ and the AP, plays a relevant role in host immune mechanisms. Previous studies have reported defects in the $\mathrm{CP}$ and AP of complement in term newborn infants as compared with adult controls (9). In the few reports also including studies of complement in low birth weight infants, classical as well as alternative complement activity have generally been found to be lower in low birth weight than in normal term infants $(1,6,8$, $14,16)$. But it is not clear from these studies whether the defect of complement activity in low birth weight infants is the result of premature birth $(6,8)$ or of intrauterine growth retardation $(1,14,16)$. The purposes of the present study were to compare complement activity of both pathways in AGA and SGA low birth weight newborns, and to determine the influence of birth weight and gestational age on complement development in such infants. Infants with infection or severe illness were excluded from the study, as were those whose mothers who reported infectious diseases during pregnancy or had prolonged rupture of membranes, in order to eliminate the influence of such factors 
on complement activity and development. Peripheral venipuncture was performed to avoid possible contamination of cord blood with maternal blood. Our data support previous reports that $\mathrm{CP}$ and AP activity in newborn infants is below the normal adult range. Activity of both pathways was significantly higher in SGA than in weight-matched AGA infants. Although the $\mathrm{CH}_{50}$ and $\mathrm{tH}_{50}$ of both pathways were highly correlated with gestational age, a significant positive correlation with birth weight was found only for $\mathrm{tH}_{50}$ of the $\mathrm{CP}$ and $\mathrm{CH}_{50}$ of the AP; however, the coefficients for the two latter correlations were relatively low. Previous studies have reported a significative correlation of complement activity with birth weight $(1,13,15)$ but this was probably due to the effect of gestational age on birth weight. In fact Shapiro et al. (15) found no differences between AGA and SGA term infants of different birth weights but comparable gestational ages. Indeed our results also show that in infants of comparable birth weights, complement activity is significantly

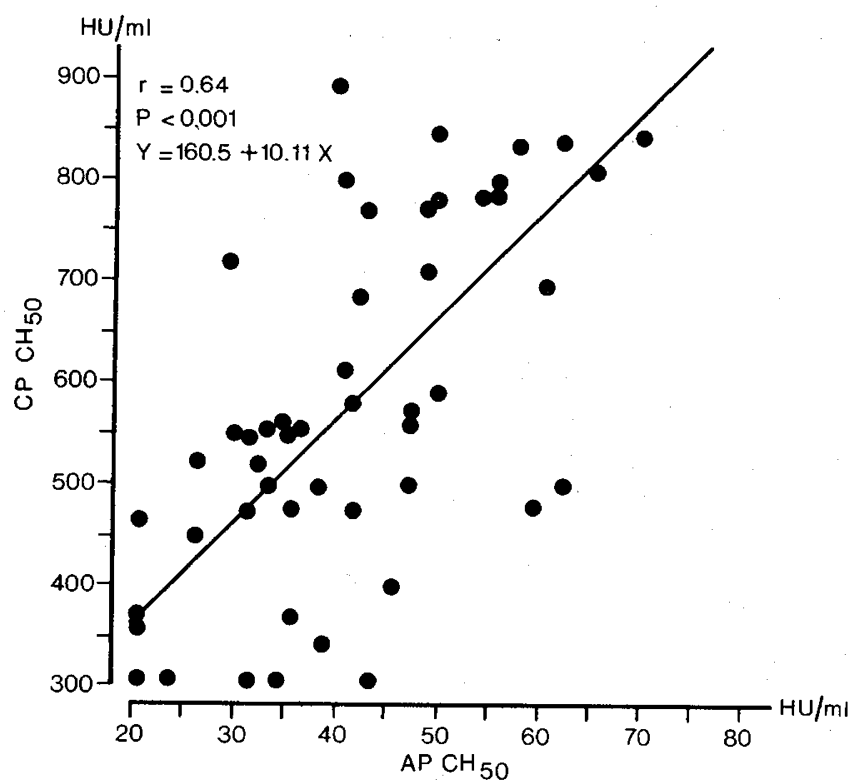

Fig. 3. Relationship of clasical pathway $\mathrm{CH}_{50}$ to alternative pathway $\mathrm{CH}_{50}$ in low birth weight newborn infants.

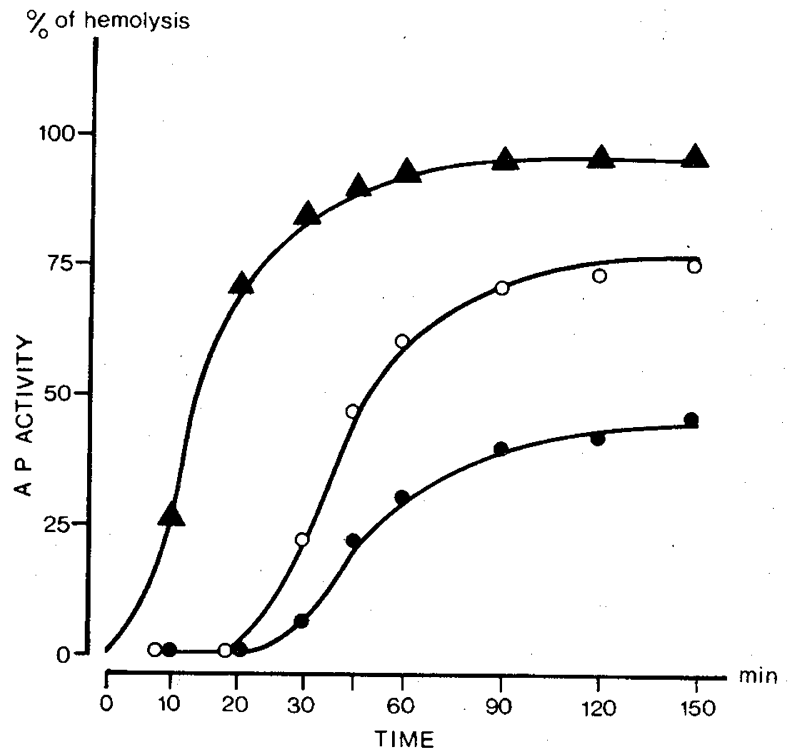

Fig. 4. Kinetic patterns of alternative pathway activation in an adult control $(\boldsymbol{\Lambda}-\mathbf{\Lambda})$, a normal term newborn $(\mathrm{O}-\mathrm{O})$ and a preterm newborn infant (0).

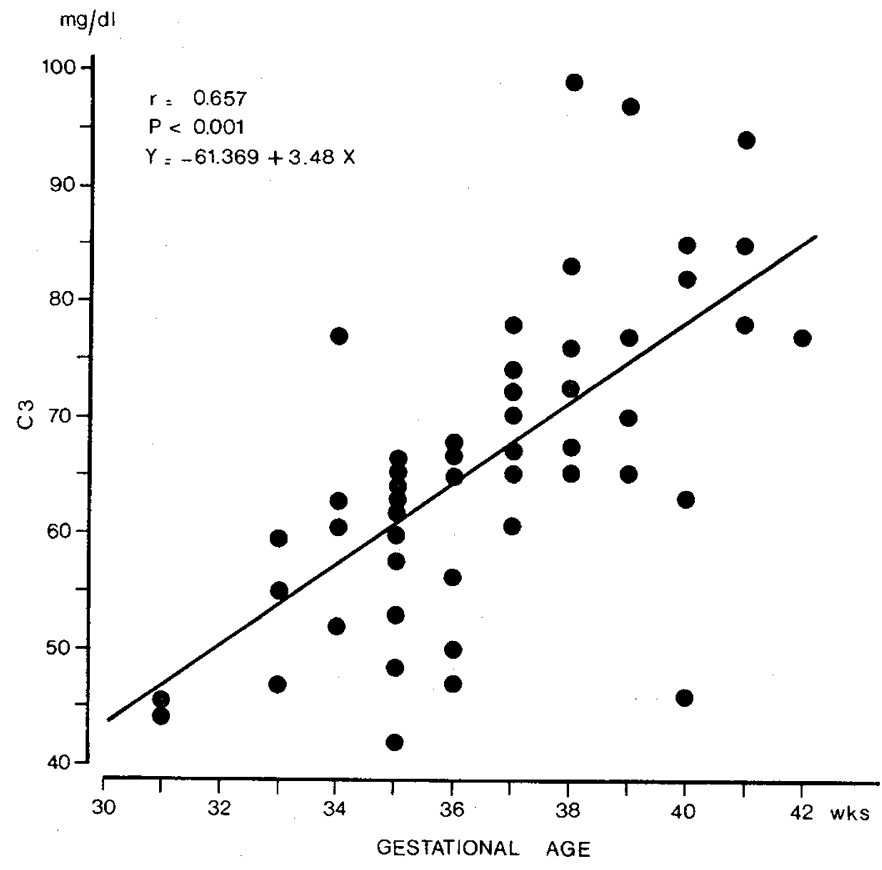

Fig. 5. Relationship of factor $\mathrm{C} 3$ serum levels to gestational age in low birth weight newborn infants.

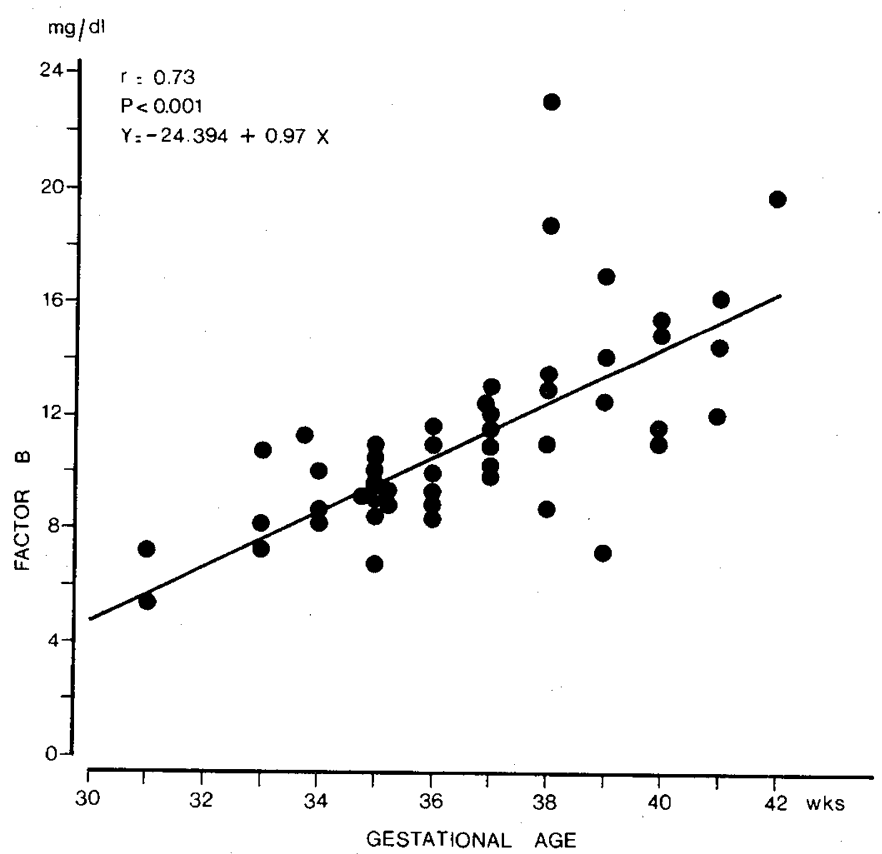

Fig. 6. Relationship of Factor B serum levels to gestational age in low birth weight newborn infants.

influenced by differences in gestational age. Furthermore, complement activity was about the same in normal term newborns and SGA. Not only $\mathrm{CH}_{50}$ and $\mathrm{tH}_{50}$ but also $\mathrm{C} 3$ and Factor $\mathrm{B}$ levels correlated better with gestational age than with birth weight. The low but still significant correlation between $\mathrm{C} 3$ or Factor $\mathrm{B}$ and birth weight and between $\mathrm{CP} \mathrm{tH}_{50}$ or AP $\mathrm{CH}_{50}$ and birth weight seems, therefore, to be due to the influence of gestational age on birth weight. Intrauterine growth retardation, therefore, does not seem to affect the development of complement activity $(6,15)$. The present data on C3 and Factor B together with previous data on the age-dependent increase of other complement factors suggest that the gradual increase of both AP and CP activities results at least partially from an age- 
dependent increase of the single complement components levels of both pathways.

Whether this increase is due to fetal production or increasing transplacental passage remains to be established; Adinolfi's data $(2,3)$ suggest that fetal production plays a major role. Certainly, the defect in early complement component levels might explain the increased susceptibility to infections as a result of defective opsonization capacity. Comparison of the kinetics of AP activation in newborn and aduit controls revealed no difference in the patterns, but a considerable delay in complement activation was evident in the low birth weight infants. Furthermore, in those AGA and SGA infants in whom the $\mathrm{CH}_{50}$ of the AP was undetectable, no lysis of RaRBC was observed even after 150 min. This phenomenon was present in eight AGA and three SGA infants suggesting that the defect of the AP may be severe especially in preterm infants and therefore of clinical relevance. An enhancing role of $\mathrm{IgG}(\mathrm{Fab})_{2}$ on the AP activity has been reported in previous studies (5) and confirmed by our experience with agammoglobulinemic sera (data not shown). We, therefore, explored the possibility that the defect in AP activation in preterm infants, as compared with term infants, could be due to the lower serum IgG level; however, the in vitro addition of up to $1600 \mathrm{mg} / \mathrm{dl}$ of IgG had no effect. Low levels of complement factors are probably the main determinant of the defective activity of both CP and AP in low birth weight infants.

The activities of both pathways were preferentially correlated with gestational age rather than birth weight and also significantly correlated with each other, suggesting a similar developmental pattern. In conclusion, low birth weight infants, especially preterm infants, have an important defect of complement activity. Complement factors increase gradually during gestation and intrauterine growth retardation does not affect complement development.

\section{REFERENCES AND NOTES}

1. Adamkin, D., Stitzel, A., Urmson, J., Farnett, M. L., Post, E., and Spitzer, R.: Activity of the alternative pathway of complement in the newborn infant. $J$. Pediatr., 93: 604 (1978)
2. Adinolfi, M.: Human complement: onset and site of synthesis during fetal life. Am. J. Dis. Child., 131: 1015 (1977).

3. Adinolfi, M., Dobson, N. C., and Bradwell, A. R.: Synthesis of two components of human complement, $\mathrm{B} 1 \mathrm{H}$ and $\mathrm{C}_{3} \mathrm{~b}$ INA, during fetal life. Acta Paediatr. Scand., 70: 705 (1981).

4. Battaglia, F. and Lubchenco, L.: A practical classification of newborn infants by weight and gestational age. J. Pediatr., 71:159 (1967).

5. Corry, J. M., Polhill, R. B. Jr., Edmonds, S. R., and Johnston, R. B. Jr.: Activity of the alternative complement pathway after splenectomy: comparison to activity in sickle cell disease and hypogammaglobulinemia J. Pediatr., 95: 964 (1979)

6. Drew, J. H. and Arroyave, C. M.: The complement system of the newborn infant. Biol. Neonate, 37: 209 (1980).

7. Dubowitz, L. M. S., Dubowitz, W., and Goldberg, C. C.: Clinical assessment of gestational age in the newborn infant. J. Pediatr., 77: 1 (1970).

8. Fireman, P., Zuchowski, D. A., and Taylor, P. M.: Development of human complement system. J. Immunol. 103: 25 (1969).

9. Johnston, R. B. Jr., Altenburger, K. M., Atkinson, A. W. Jr., and Curry, R. H.: Complement in the newborn infant. Pediatrics, 64: (Suppl) 781 (1979).

10. Johnston, R. B. Jr. and Stroud, R. M.: Complement and host defense against infection. J. Pediatr., 90: 169 (1977)

11. Mayer, M. M.: "Complement and complement fixation" In: KABAT E. A. and MAYER M. M. Exp. Immunochem. 2nd ed. (Charles C. Thomas, Publisher, Springfield, IL p. 133 1961).

12. Notarangelo, L. D., Plebani, A., Marconi, M., Chiara, A., Martini, A., and Ugazio, A. G.: A simple hemolytic micromethod for the quantitative and kinetic evaluation of the alternative pathway of complement. La. Ricerca Clin. Lab., (in press 1983).

13. Platts-Mills, T. and Ishizaka, K.: Activation of the alternative pathway of human complement by rabbit cells. J. Immunol., 113: 348 (1974).

14. Sawyer, M. K., Forman, M. L., Kuplic, L. S., and Stiehm, E. R.: Developmental aspects of the human complement system. Biol. Neonate, 19: 148 (1971).

15. Shapiro, R., Beatty, D. W., Woods, D. L., and Malan. A. F.: Serum complement and immunoglobulin values in small-for-gestational-age infants. J. Pediatr., 99: $139(1981)$

16. Strunk, R. C., Fenton, I. J., and Gaines, J. A.: Alternative pathway of complement activation in full term and premature infants. Pediatr. Res., 13: 641 (1979).

17. The authors thank Prof. G. R. Burgio for his encouragement and support and Dr. V. Monafo for her critical revision of the manuscript. Authors are also grateful to Mr. A. Ascione for his skillful technical assistance and to Mr. L. Lisca for her invaluable secretarial assistance.

18. This study was partly supported by CNR, Roma

19. Requests for reprints should be addressed to: Dr. Luigi D. Notarangelo, Department of Pediatrics, San Matteo Hospital, 27100 Pavia, Italy.

20. Received for publication April 22, 1982.

21. Accepted for publication May 12, 1983.

\section{Announcement}

2nd Annual Infectious Disease Conference

PLACE: Hyatt Regency Columbus Hotel 350 North High Street

Columbus, Ohio 43215

DATE: Wednesday, April 4, 1984

SPONSOR: Children's Hospital Columbus, Ohio

CONTACT PERSON: Becky Martin, Program Coordinator

Department of Education

Children's Hospital

700 Children's Drive

Columbus, Ohio 43205

(614) 461-2914 